\title{
Pollution levels and the effect of air pollution on asthma hospitalisations modified by synoptic weather type and aeroallergens
}

\author{
S. Cakmak \& C. Hebbern \\ Environmental Health Research Bureau, Population Studies Division, \\ Health Canada, Canada
}

\begin{abstract}
Pollution levels and the effect of air pollution on human health can be modified by synoptic weather type and aeroallergens. We investigated the effect modification of aeroallergens on the association between $\mathrm{CO}, \mathrm{O}_{3}, \mathrm{NO}_{2}, \mathrm{SO}_{2}$, $\mathrm{PM}_{10}$ and $\mathrm{PM}_{2.5}$ and asthma hospitalisation rates in seven synoptic weather types using single air pollutant models, adjusted for the effect of aeroallergens and stratified by synoptic weather type, with pooled relative risk estimates for asthma hospitalisation in ten Canadian cities. Aeroallergens significantly modified the relative risk in 19 pollutant-weather type combinations, reducing the size and variance for each single pollutant model. Aeroallergens did not significantly modify relative risk for any pollutant in the DT or MT weather types, or for $\mathrm{PM}_{10}$ in any weather type. There is an interactive effect between aeroallergens and $\mathrm{CO}$, $\mathrm{O}_{3}, \mathrm{NO}_{2}, \mathrm{SO}_{2}$, and $\mathrm{PM}_{2.5}$, on asthma hospitalisations that differs under specific synoptic weather types.
\end{abstract}

Keywords: asthma, hospitalisation, aeroallergens, allergy, air pollution, epidemiology, SSC, spatial synoptic classification.

\section{Introduction}

The association of individual climatological variables, such as temperature, with human health outcomes has been well studied, and while this approach can draw meaningful associations between weather predictors and mortality or morbidity it can fail to capture the complex effect of interrelated weather factors on human physiology. To account for this, spatial synoptic classification (SSC) can be used to group weather patterns using a suite of meteorological parameters into distinct 
categories [1]. The SSC is becoming more widely used to investigate associations between pollutant levels and mortality; one study found that ozone in conjunction with dry tropical and moist tropical weather types increased the risk of hospitalisation for asthma and myocardial infarction [2].

Synoptic weather patterns have been found to affect concentrations of air pollutants [3-5]; however, the implications of this for human health are not clear. Weather types can affect human health outcomes in their own right due to their intrinsic meteorological characteristics: the so called "offensive" SSCs, DT, dry tropical, and MT, moist tropical, have been found to increase mortality rates, and this effect increases with the duration of exposure to the weather type [6, 7].

Our recent work found air pollution modifies the effect of aeroallergens on asthma, increasing the rate of hospitalisations on days of high air pollution [8]. These findings were consistent with both animal model and human studies that suggested biological interactions between pollutants and aeroallergens [9-12]. Airways damaged by air pollutants may be more susceptible to allergen exposure [13], while population level studies support an interactive effect between pollution and aeroallergens $[14,15]$.

Aeroallergen levels may be increased by synoptic weather conditions such as low height and stability in the nocturnal boundary layer [16] or low surface pressures [17]. The relationship between pollution, aeroallergens, and asthma is therefore complex, and there is potential for further modification of this relationship by weather type, due to intrinsic characteristics of the weather type itself that can directly affect human health or by the weather type affecting pollutant and aeroallergen levels.

In this study we explore the relative risk of asthma hospitalisation from single air pollutants and the modifying effect of aeroallergens, pooled for ten cities across Canada, in the presence of seven synoptic scale weather types.

\section{Methods}

The study population comprised hospitalisations where asthma was recorded as principal reason for admission, obtained from the Canadian Institute for Health Information (CIHI), for 10 cities across Canada: Calgary, Edmonton, Halifax, London, Ottawa, Saint John, Toronto, Vancouver, Windsor, and Winnipeg. Data was obtained for the period April 1, 1994 to March 31, 2007 with city population data centred on 2000 .

Air pollution data for each city were obtained from the National Air Pollution Monitoring System as one hour maximum daily ozone concentrations, 24 hour concentrations of carbon monoxide, nitrogen dioxide, and sulphur dioxide, and particulate matter with mean aerodynamic diameters of $10\left(\mathrm{PM}_{10}\right)$ and $2.5 \mu \mathrm{m}$ $\left(\mathrm{PM}_{2.5}\right)$.

Aeroallergens were collected by Aerobiology Research Laboratories, using a standardised method for all cities. Rotational impact methods were used to obtain 24 hour collections of pollen grains and fungal spores and estimate the number of particles present per cubic meter of air sampled. 
Spatial Synoptic Classification combines routinely collected meteorological variables (air temperature, dew point, wind velocity, pressure, and cloud cover) in order to classify a weather situation into one of six weather types, dry moderate (DM), dry polar (DP), dry tropical (DT), moist moderate (MM), moist polar (MP), moist tropical (MT), plus a transition category (TR) where one weather type yields to another. The SSC is a semi-automated classification system developed and maintained by Sheridan [1]. The data used for classification is obtained from the Meteorological Service of Canada from airport weather stations in each of the ten cities. Daily synoptic weather classifications for each city are available at the SSC archive (http://sheridan.geog.kent.edu/ssc.html).

Generalised additive models (S-Plus 6.0.2 (1)) with stringent convergence criteria $(\&)<10^{-14}$ ) were used to test the association between asthma hospitalisations and individual pollutants, adjusting for the interactive effect of aeroallergens. Each model was developed for days corresponding to one of seven synoptic scale weather types. We assumed that the hospitalisation data was Poisson-distributed. Natural cubic splines were used to model seasonal and longterm trends with knots spaced at 13, 25, 49 and 145 days of observation, the number of knots selected based on optimisation of Akaike's Information Criteria (AIC) and the Bartlett test for autocorrelation. Day of week was included as an indicator variable. The effect of each pollutant on asthma hospitalisation was tested for the day of admission and five days preceding admission (lags 0, 1, 2, 3, $4,5)$, selecting the lag period which optimised the observed effect size. Relative risks were estimated for an interquartile increase $\left(25^{\text {th }}\right.$ to $\left.75^{\text {th }}\right)$ in hospitalisation for asthma, stratified by weather type. The relative risks of asthma hospitalisation for each pollutant were tested with and without adjustment for the effect of aeroallergens for days in the presence of each weather type. A $z$-test was used to test for significant differences $(\mathrm{P}<0.05)$ in $\mathrm{RR}$ before and after adjustment by aeroallergens for each single-pollutant model within each weather type.

Data was pooled for the ten cities using a random effects model with a random intercept to account for between-city inhomogeneity, and the effect estimates were weighted using the inverse sum of within and between-city variance, as in Cakmak et al. [8]. Single-pollutant-specific regression coefficients were combined using the restricted maximum likelihood method.

\section{Results}

The frequency of occurrence of the seven weather types during the study period is presented in Table 1. The Canadian cities used in this study are spread across a large region and experience a varied climate, with some notable national and regional trends. The dry moderate (DM) and moist moderate (MM) weather types are the most frequent across all cities, while the least common were the dry tropical (DT) and moist tropical (MT) weather types, both considered "offensive" for their association with adverse health endpoints. Regionally, the 
Table 1: $\quad$ Weather type frequency (\%) per city and the average frequency for all cities during the study period, for seven weather types: DM (dry moderate), DP (dry polar), DT (dry tropical), MM (moist moderate), MP (moist polar), MT (moist tropical), and TR (transitional).

\begin{tabular}{llllllll}
\hline & DM & DP & DT & MM & MP & MT & TR \\
\hline Calgary & 31 & 23 & 3 & 9 & 19 & 1 & 8 \\
Edmonton & 21 & 32 & 2 & 8 & 22 & 1 & 12 \\
Halifax & 23 & 18 & 1 & 18 & 13 & 8 & 9 \\
London & 27 & 11 & 4 & 19 & 7 & 20 & 8 \\
Ottawa & 29 & 11 & 5 & 21 & 9 & 14 & 9 \\
Saint John & 18 & 13 & NA & 21 & 26 & 6 & 11 \\
Toronto & 34 & 8 & 7 & 17 & 5 & 18 & 10 \\
Vancouver & 44 & 3 & NA & 28 & 13 & 1 & 9 \\
Windsor & 26 & 12 & 5 & 18 & 5 & 23 & 7 \\
Winnipeg & 27 & 16 & 2 & 16 & 13 & 12 & 11 \\
\hline All-city & 28 & 15 & 3 & 17 & 13 & 10 & 10 \\
average & & & & & & & \\
\hline
\end{tabular}

dry polar (DP) weather type was most common in the prairies and on the East Coast and least frequent in Toronto and Vancouver.

Asthma admission rates per 100,000 varied by weather type and city (Table 2). Rates of admission were lowest in the DT and MT weather types, at 17.6 and 30.1 per 100,000 respectively for all cities. The highest all city admission rate was recorded for the DP weather type, at 220.6 admissions per 100,000 , although this varied from a low of 35.5 in Vancouver to 392.6 in Halifax. The highest individual city rate of admissions for asthma was recorded in Halifax, at 434.1 per 100,000 in the MP weather type.

Aeroallergen levels varied between cities and by weather type (Figure 1). Basidiomycetes spore concentrations were highest in Ottawa in MM, DT, DM, and MT weather types and lowest in all cities in the DP weather type. Concentrations ranged from 4.83 counts in Edmonton in DT air to 1343 counts in Ottawa in the MT type. Ascomycetes concentrations ranged from 9.05 grains $/ \mathrm{m}^{3}$ in Halifax in DP to 1418 in Ottawa in the MM weather type. Fungi imperfecti concentrations ranged from 5.59 grains $/ \mathrm{m}^{3}$ in Halifax in the DP weather type, to 4389.3 grains $/ \mathrm{m}^{3}$ in Ottawa in the MT type. For all three fungal aeroallergens, means were clustered most tightly in the DP weather type. 
Table 2: Asthma admissions per 100,000 city population, and the average rate of admissions for all cities during the study period, for seven weather types: DM (dry moderate), DP (dry polar), DT (dry tropical), MM (moist moderate), MP (moist polar), MT (moist tropical), and TR (transitional).

\begin{tabular}{llllllll}
\hline & DM & DP & DT & MM & MP & MT & TR \\
\hline Calgary & 316.6 & 276.5 & 27.1 & 87.3 & 221.5 & 2.5 & 87.1 \\
Edmonton & 199.4 & 307.1 & 18.9 & 84.1 & 212.9 & 2.5 & 126.2 \\
Halifax & NA & 392.6 & 4.4 & 250.3 & 434.1 & 47.2 & 188.4 \\
London & 169.6 & 108.1 & 19.3 & 113.4 & 122.3 & 63.1 & 81.2 \\
Ottawa & 162.7 & 173.8 & 16.2 & 117.5 & 105.1 & 32.7 & 78.8 \\
Saint John & 73.7 & 150.8 & NA & 146.1 & NA & 22.5 & 132.4 \\
Toronto & 337.0 & 181.0 & 33.5 & 184.2 & 178.2 & 80.3 & 133.0 \\
Vancouver & 208.0 & 35.5 & NA & 307.2 & 226.0 & 14.3 & 88.6 \\
Windsor & NA & 275.7 & 39.2 & 237.5 & 192.3 & NA & 142.6 \\
Winnipeg & 229.0 & 305.0 & 16.4 & 166.2 & 198.0 & 36.0 & 127.7 \\
\hline All-city & 169.6 & 220.6 & 17.6 & 169.4 & 189.0 & 30.1 & 118.6 \\
average & 169.6 & & & & \\
\hline
\end{tabular}

Regional differences were clearer for pollen counts, with the lowest values for weed pollen and grass pollen found consistently in Halifax and Saint John, on the East Coast, and the highest values for tree pollen in Vancouver on the West Coast. Weed pollen concentrations ranged from 27 counts $\mathrm{m}^{3}$ in Winnipeg in MT to 1.09 counts $\mathrm{m}^{3}$ in MP in Halifax. The highest concentration of tree pollen was found in Vancouver in MM, 180.5 counts $/ \mathrm{m}^{3}$, and the lowest in Edmonton in the MP weather type. Grass pollen concentrations were highest in Windsor in DT, at 61.3 counts per $\mathrm{m}^{3}$, and lowest in Halifax and Saint John in all weather types.

Mean daily air pollutant levels varied by city and weather type, with regional differences also present (Figure 2). CO concentrations ranged from $0.18 \mathrm{ppb}$ in London DP weather to $0.96 \mathrm{ppb}$ in Toronto in MM. In all seven weather types, the highest and lowest values were found in Toronto and London respectively; Halifax and Saint John tended to be toward the higher end of the range while the prairie cities Winnipeg, Edmonton, and Calgary, toward the lower, in all weather types. $\mathrm{CO}$ concentrations were not highly variable by weather type, however. Mean daily $\mathrm{O}_{3}$ concentrations ranged from $27 \mathrm{ppb}$ in Winnipeg in the MP weather type to $81.8 \mathrm{ppb}$ in Windsor in DT. The highest values were in the Great Lakes cities of Windsor, Toronto, and London, in the DT and MT weather types. Mean values were least dispersed in DP and MP weather types, remaining low 


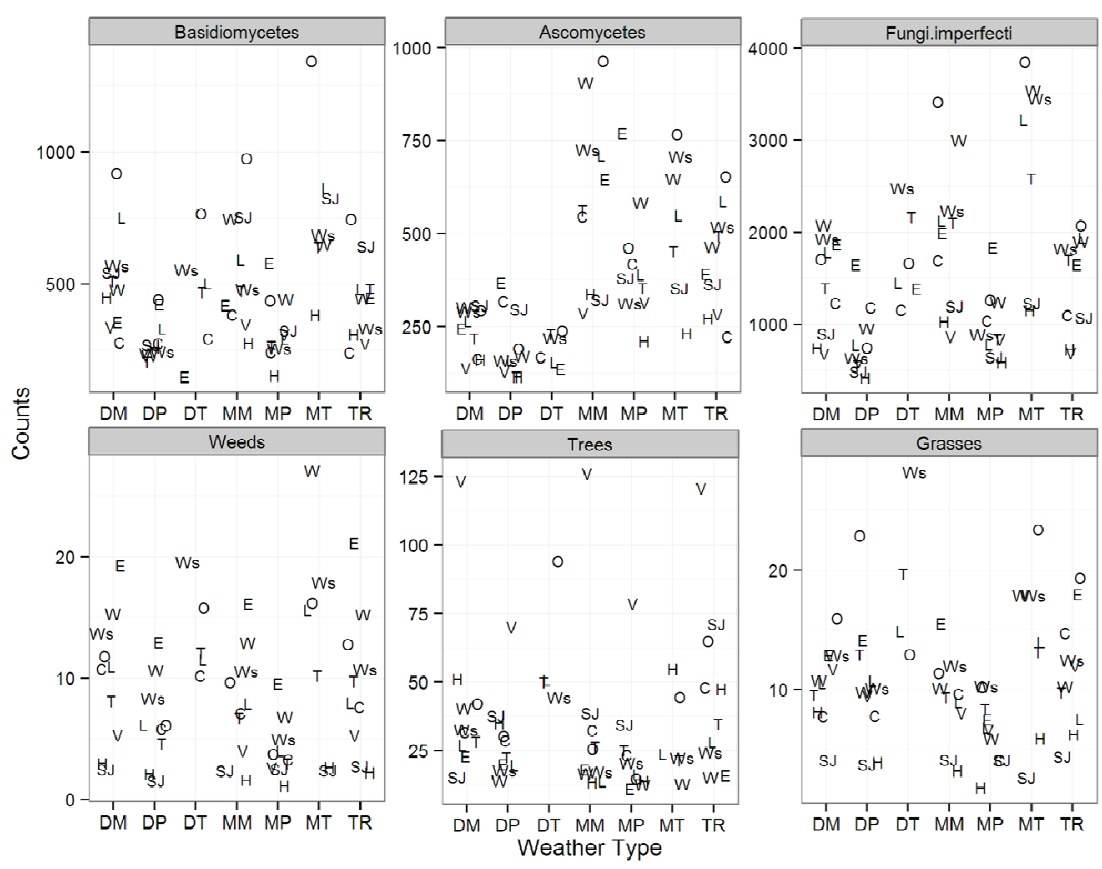

Figure 1: $\quad$ Mean concentrations of aeroallergens by city for the study period of April to October, 1994 to 2007. C: Calgary; E: Edmonton; H: Halifax; L: London; O: Ottawa; SJ: Saint John; T: Toronto; V: Vancouver; Ws: Windsor, W: Winnipeg.

for all cities examined. $\mathrm{NO}_{2}$ concentrations were highest in Toronto and Windsor in all weather types and lowest in Winnipeg and Saint John in all weather types. The highest mean concentration of $\mathrm{NO}_{2}, 29.3 \mathrm{ppb}$, was in Toronto in DT weather. Mean concentrations of $\mathrm{SO}_{2}$ ranged from 1.39 in Edmonton in MP air to $14 \mathrm{ppb}$ in Windsor in DT weather. With the exception of the DT weather type, the highest mean concentrations of $\mathrm{SO}_{2}$ were found in the East Coast cities Halifax and Saint John. Particulate matter concentrations ranged from 7.87 for $\mathrm{PM}_{10}$ in Vancouver in the MP weather type, to 48.6 particulates $\mu \mathrm{g} / \mathrm{m}^{3}$ in Windsor in MT (cities with fewer than 50 observations were excluded from these figures). The effect of weather type is more apparent in $\mathrm{PM}_{2.5}$, where mean particulate concentrations range from 2.62 in Halifax in MP air, to $30 \mu \mathrm{g} / \mathrm{m}^{3}$ in London in MT air. $\mathrm{PM}_{2.5}$ counts are lowest in the DP and MP weather types, and highest in the DT and MT weather types.

The single pollutant models found significant increases in relative risk for asthma hospital admissions in the general population (Figure 3), with the exception of $\mathrm{PM}_{10}$ in the DT weather type. After adjustment for the interactive effect of aeroallergens the relative risk of hospitalisation declined, but remained 


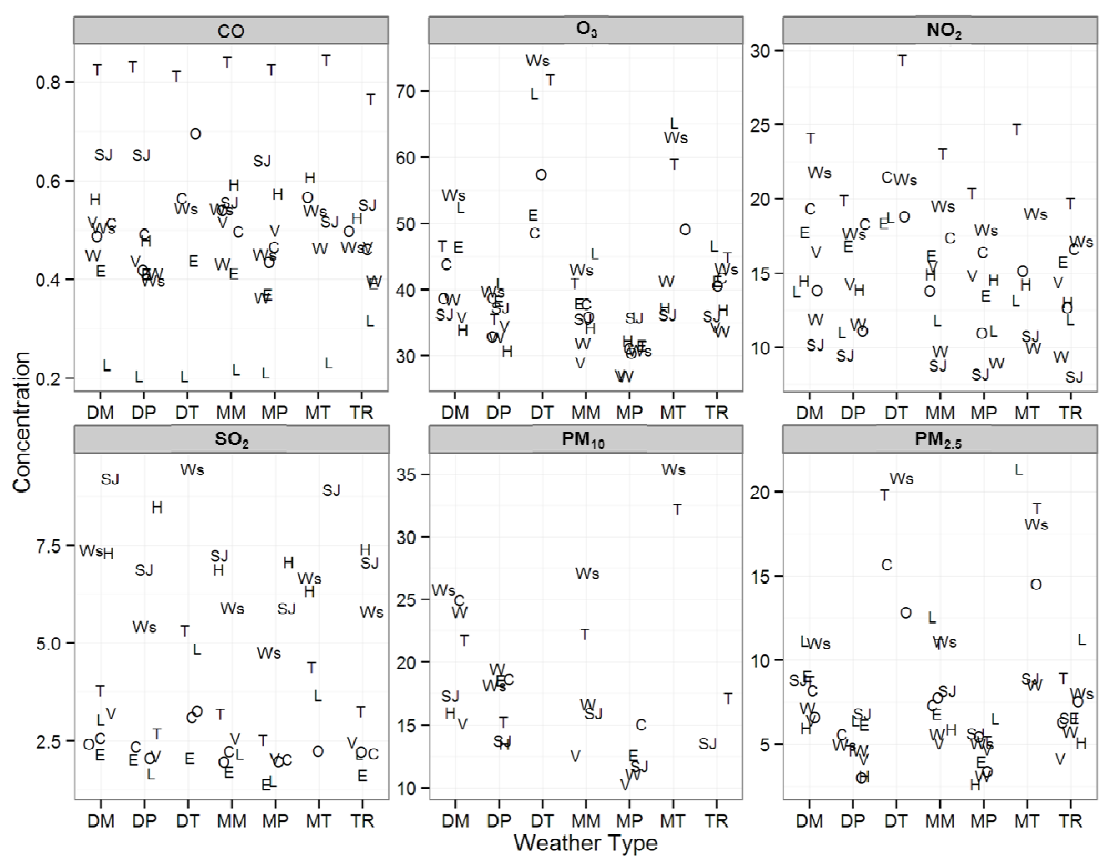

Figure 2: $\quad$ Mean pollutant concentrations by city for the study period of April to October, 1994 to 2007. C: Calgary; E: Edmonton; H: Halifax; L: London; O: Ottawa; SJ: Saint John; T: Toronto; V: Vancouver; Ws: Windsor, W: Winnipeg.

above 1.0 in all pollutants in all weather types, with the exception of $\mathrm{O}_{3}$ and $\mathrm{PM}_{10}$, both in DT.

Significant $(\mathrm{P} \leq 0.05)$ differences in relative risk of asthma hospitalisations from air pollutants after adjustment for the interactive effect of aeroallergens were found for $\mathrm{CO}, \mathrm{O}_{3}, \mathrm{NO}_{2}, \mathrm{SO}_{2}$, and $\mathrm{PM}_{2.5}$. There were no significant changes in RR after adjustment for aeroallergens in any weather type for $\mathrm{PM}_{10}$, and no significant differences in RR in DT or MT for any of the pollutants.

Aeroallergens significantly increased the effect size of air pollutants in 19 of the 42 cases (pollutant and weather type) examined. The largest interactive effect was found for $\mathrm{CO}$, in the MP weather type, where the RR of asthma hospitalisation increased from 1.065 (95\% CI, 1.032-1.098) to 1.282 (95\% CI, 1.163-1.413), and the second largest was for CO in the MM weather type, where RR increased from 1.059 (95\% CI, 1.027-1.092) to 1.236 (95\% CI, 1.158-1.32). In the TR weather type, aeroallergens increased the effect size of $\mathrm{NO}_{2}$ on asthma hospital admissions from 1.055 (95\% CI, 1.012-1.098) to 1.218 (95\% CI, 1.1251.319). The fourth largest increase in effect size was again for $\mathrm{CO}$, in the DP weather type, which increased the RR from 1.04 (95\% CI, 1.009-1.073) to 1.187 (95\% CI, 1.081-1.303). 

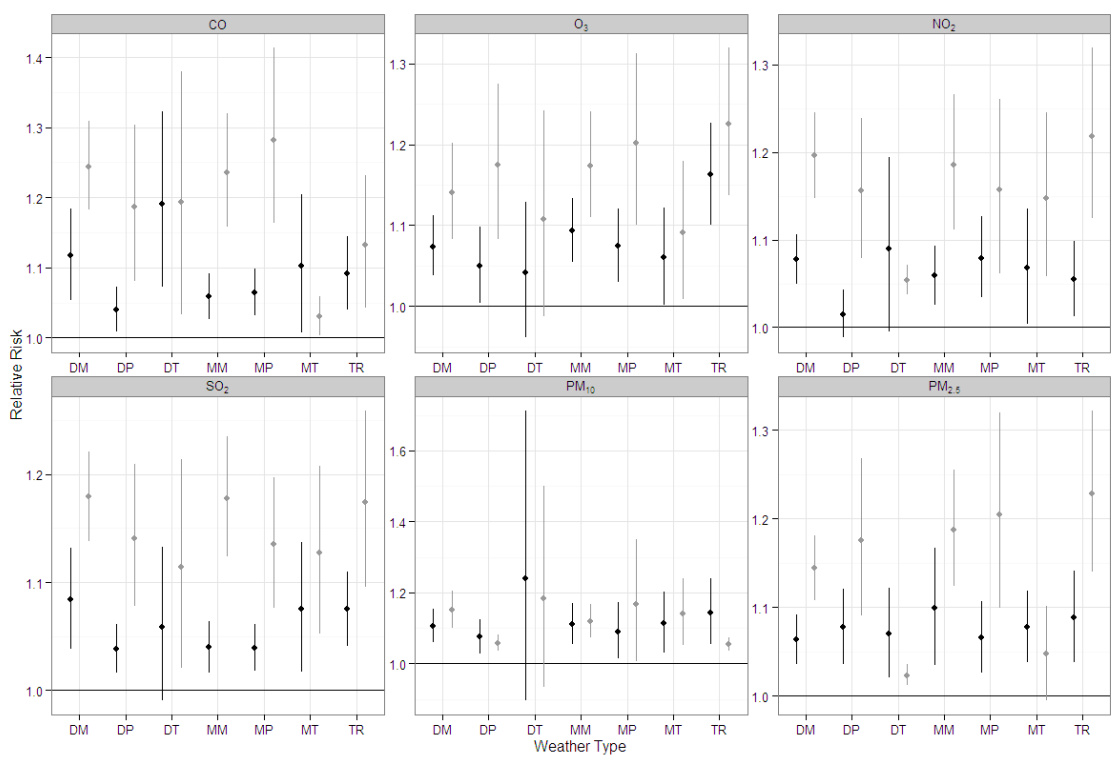

Figure 3: Pooled estimates of relative risks of hospitalisation for asthma among ten cities, before (black) and after (grey) adjustment for aeroallergens. Bars represent $95 \%$ confidence intervals.

The interactive effect of aeroallergens on air pollution was significant for $\mathrm{SO}_{2}$ for the DM, DP, MM, MP, and TR weather types, with the largest change after adjustment for aeroallergens in MM air, from 1.04 (95\% CI, 1.016-1.064) to 1.178 (95\% CI, 1.124-1.235); whereas for $\mathrm{O}_{3}$ it was significant only in two of the weather types: DP, increasing from 1.05 (95\% CI, 1.004-1.098) in the unadjusted model to $1.175(95 \% \mathrm{CI}, 1.083-1.275)$ in the adjusted model, and in the MM weather type, from $1.094(95 \% \mathrm{CI}, 1.055-1.134)$ to $1.174(95 \% \mathrm{CI}$, 1.11-1.241).

In the DP weather type, the effect estimate of pollutants on asthma hospitalisations was significant after adjustment for aeroallergens for all of the pollutants except $\mathrm{PM}_{10}$, with the largest increase for $\mathrm{CO}$ and the smallest for $\mathrm{PM}_{2.5}$, where RR went from 1.077 (95\% CI, 1.035-1.121) to 1.175 (1.09-1.268).

\section{Discussion}

Pollutants exacerbate asthma $[9,18,19]$ and have been associated with increased emergency hospitalisations $[20,21]$. Aeroallergens also exacerbate asthma both independently [22] and in interaction with air pollution [8, 23, 24].

The present study also finds that aeroallergens positively influence the relationship between air pollution and asthma, and that this interactive effect can be modified by the synoptic weather type present. This latter finding is consistent with a study of asthma admissions in New York City, that showed cold and dry 
weather types (DT and DP) to be associated with spikes in asthma hospitalisations [25]. While we also observed an increased RR of asthma hospitalisation in the DT weather type in all the single pollutant models, it was insensitive to adjustment for aeroallergens; however, this weather type was also the least frequently experienced in Canada. For the DP weather type, RRs were consistently elevated in all the pollutant models except for $\mathrm{PM}_{10}$, and in each case except $\mathrm{PM}_{10}$ were significantly reduced after adjustment for aeroallergens. Dry, cold, DP-type weather is typically associated with asthma exacerbation [26] and this weather type is the third most commonly experienced in Canada, with the highest overall rate of asthma admissions.

DT and MT are associated with high mortality due to the effects of heat [27]; however, we found the effect of these two weather types on asthma hospitalisations to be less pronounced. The highest RR was for carbon monoxide in the MP weather type, and it was also one of the pollutant models most affected by adjustment for aeroallergens. There is some evidence that carbon monoxide is associated with asthma exacerbation [28], and our recent work comparing low and high air pollution also found significant increases in hospitalisations for $\mathrm{CO}$ with increases in the aeroallergens ascomycetes, basidiomycetes, and deuteromycetes equivalent to their pooled interquartile ranges [8].

There is consistent evidence that ozone is associated with asthma [29], that it interacts significantly with allergens, possibly by priming airways for inflammation [10], and that it can be modified by weather type [2]. The highest RR of asthma hospitalisation in the present study was found for ozone in the TR, transitional, weather type, as was also found by Hanna et al. [2]. However, we did not observe as large an effect for DT weather; DP and MP were more important, likely related to the greater frequency of occurrence of these types in Canada.

The RR of $\mathrm{PM}_{10}$ exposure on asthma hospitalisations was not significantly affected by adjustment for aeroallergens in any of the seven weather types. This is consistent with confounding of the results as fungal spores and pollen also fall within the particulate size range encompassed by $\mathrm{PM}_{10}$. Additionally, while the $\mathrm{PM}_{10}$ model did find elevated $\mathrm{RR}$, the effect size was lower than for any of the other pollutants. The effect of $\mathrm{PM}_{10}$ on asthma is not considered to be as great as that of $\mathrm{PM}_{2.5}$. While one study in Canada found an effect of $\mathrm{PM}_{10}$ on asthma admissions and none for $\mathrm{PM}_{2.5}$ [30], the greater effect of $\mathrm{PM}_{2.5}$ is supported by laboratory studies. $\mathrm{PM}_{2.5}$ has been shown to be more associated with oxidative stress in rat lung epithelial cells than $\mathrm{PM}_{10}$, suggesting it may be more involved in asthma exacerbation [31]. A number of human studies further support a role for $\mathrm{PM}_{2.5}$ in the etiology of asthma exacerbations [32-34].

For $\mathrm{NO}_{2}$ and $\mathrm{SO}_{2}$, we found the highest RR occurred in the DM weather type, and in both cases this was significantly different after adjustment for aeroallergens. Our findings suggest an additional interactive effect for $\mathrm{SO}_{2}$ and aeroallergens.

Study limitations: pooling the effect size estimates was necessary to obtain sufficient statistical power, but heterogeneity in the dataset, from using ten cities 
spaced across a wide geographical range, limits the applicability of these findings to individual cities. While we found regional similarities the cities vary in pollution levels and types of vegetation and thus exposure to aeroallergens, and also in socioeconomic factors, which may affect how the population responds to environmental stress. Some of the weather types were relatively infrequent in Canada and the SSC approach is a relative, rather than absolute, classification. As a result, comparisons between synoptic weather types in Canada may not be readily comparable elsewhere. Insufficient numbers of observations for aeroallergens in some of the weather types likely contributed to the higher confidence intervals. This situation arises as the pollen season for trees, grasses, and weeds, peak at different times of the year and do not persist for as long as that of fungal spores, and pooling the aeroallergen counts, as was done here, limits exploration of these differences.

\section{Conclusions}

Synoptic weather types are known to modify levels of air pollution and aeroallergens. The dry polar, moist moderate, moist polar and transitional weather types present the highest relative risks of asthma hospitalisation, and this risk can be modified by adjustment for aeroallergens. Synoptic forecasting may help prepare for and mitigate spikes in asthma admission rates, particularly when used in combination with information on airborne allergens.

\section{References}

[1] Sheridan SC. The redevelopment of a weather-type classification scheme for North America. Int J Climatol, 22, pp. 51-68, 2002.

[2] Hanna AF, Yeatts KB, Xiu A, Zhu Z, Smith RL, Davis NN, et al. Associations between ozone and morbidity using the Spatial Synoptic Classification system. Environ Heal, 10, 49, 2011.

[3] Greene JS, Kalkstein LS, Ye H, Smoyer K. Relationships between synoptic climatology and atmospheric pollution at 4 US cities. Theor Appl Climatol, 62, pp. 163-74, 1999.

[4] Rainham DDDGC, Smoyer-Tomic KKE, Sheridan SCS, Burnett RTR. Synoptic weather patterns and modification of the association between air pollution and human mortality. Int J Environ Health Res, 15, pp. 347-60, 2005.

[5] Davis RE, Normile CP, Stika L, Hondula DM, Knight SD, Gawtry SDP, et al. A comparison of trajectory and air mass approaches to examine ozone variability. Atmos Environ, 44, pp. 64-74, 2010.

[6] Sheridan SC, Kalkstein AJ. Seasonal variability in heat-related mortality across the United States. Nat Hazards, 55, pp. 291-305, 2010.

[7] Kyselý J. Implications of enhanced persistence of atmospheric circulation for the occurrence and severity of temperature extremes. Int J Climatol, 27, pp. 689-95, 2007. 
[8] Cakmak S, Dales RE, Coates F. Does air pollution increase the effect of aeroallergens on hospitalization for asthma? J Allergy Cinical Immunol, 129, pp. 228-31, 2012.

[9] Peden DB. Air pollution in asthma: effect of pollutants on airway inflammation. Ann Allergy, Asthma Immunol, 87, pp. 12-7, 2001.

[10] Kehrl H, Peden D, Ball B. Increased specific airway reactivity of persons with mild allergic asthma after 7.6 hours of exposure to $0.16 \mathrm{ppm}$ ozone. $\mathrm{J}$ Allergy Clin Immunol, 104, pp. 1198-204, 1999.

[11] Farraj AK, Haykal-Coates N, Ledbetter AD, Evansky PA, Gavett SH. Neurotrophin mediation of allergic airways responses to inhaled diesel particles in mice. Toxicol Sci, 94, pp. 183-92, 2006.

[12] Whitekus MJ, Li N, Zhang M, Wang M, Horwitz M a, Nelson SK, et al. Thiol antioxidants inhibit the adjuvant effects of aerosolized diesel exhaust particles in a murine model for ovalbumin sensitization. J Immunol, 168, pp. 2560-7, 2002.

[13] Amato GD, Cecchi L, Amato MD, Liccardi G. Urban Air Pollution and Climate Change as Environmental Risk Factors of Respiratory Allergy: An Update. J Investig Allergol Clin Immunol, 20, pp. 95-102, 2010.

[14] Johnston NW, Sears MR. Asthma exacerbations. 1: epidemiology. Thorax, 61, pp. 722-8, 2006.

[15] Atkinson RW, Strachan DP. Role of outdoor aeroallergens in asthma exacerbations: epidemiological evidence. Thorax, 59, pp. 273-4, 2004.

[16] Gassmann M, Gardiol J. Weather conditions associated with the potential for pollen recirculation in a coastal area. Meteorol Appl, 48, pp. 39-48, 2007.

[17] Hart MA, de Dear R, Beggs PJ. A synoptic climatology of pollen concentrations during the six warmest months in Sydney, Australia. Int J Biometeorol, 51, pp. 209-20, 2007.

[18] Strachan DP. The role of environmental factors in asthma. Br Med Bull, 56, pp. 865-82, 2000.

[19] Islam T, Gauderman WJ, Berhane K, McConnell R, Avol E, Peters JM, et al. Relationship between air pollution, lung function and asthma in adolescents. Thorax, 62, pp. 957-63, 2007.

[20] Tobías A, Galán I, Banegas JR. Non-linear short-term effects of airborne pollen levels with allergenic capacity on asthma emergency room admissions in Madrid, Spain. Clin Exp Allergy, 34, pp. 871-8, 2004.

[21] Cheng M-F, Tsai S-S, Chiu H-F, Sung F-C, Wu T-N, Yang C-Y. Air pollution and hospital admissions for pneumonia: are there potentially sensitive groups? Inhal Toxicol, 21, pp. 1092-8, 2009.

[22] Dales RE, Cakmak S, Judek S, Dann T, Coates F, Brook JR, et al. Influence of outdoor aeroallergens on hospitalization for asthma in Canada. J Allergy Cinical Immunol, 113, pp. 303-6, 2004.

[23] Watanabe M, Igishi T, Burioka N, Yamasaki A, Kurai J, Takeuchi H, et al. Pollen augments the influence of desert dust on symptoms of adult asthma patients. Allergol Int, 60, pp. 517-24, 2011. 
[24] Burt P, Sharma P. Effects of aeroallergens on the lung function of primary school children at two contrasting sites in South-East England. Aerobiologia (Bologna), 18, pp. 125-34, 2002.

[25] Lee CC, Sheridan SC, Lin S. Relating Weather Types to Asthma-Related Hospital Admissions in New York State. Ecohealth 2012.

[26] D'Amato G, Cecchi L. Effects of climate change on environmental factors in respiratory allergic diseases. Clin Exp Allergy, 38, pp. 1264-74, 2008.

[27] Sheridan SC, Kalkstein AJ, Kalkstein LS. Trends in heat-related mortality in the United States, 1975-2004. Nat Hazards, 50, pp. 145-60, 2009.

[28] Peel JL, Tolbert PE, Klein M, Metzger KB, Flanders WD, Todd K, et al. Ambient Air Pollution and Respiratory Emergency Department Visits. Epidemiology, 16, pp. 164-74, 2005.

[29] Galan I, Tobias A, Banegas JR, Aranguez E. Short-term effects of air pollution on daily asthma emergency room admissions. Eur Respir J, 22, pp. 802-8, 2003.

[30] Lin M, Chen Y, Burnett R. The influence of ambient coarse particulate matter on asthma hospitalization in children: case-crossover and timeseries analyses. Environ Health Perspect, 110, pp. 575-81, 2002.

[31] Choi J-H, Kim J-S, Kim Y-C, Kim Y-S, Chung N-H, Cho M-H. Comparative study of $\mathrm{PM}_{2.5}$ - and $\mathrm{PM}_{10}$ - induced oxidative stress in rat lung epithelial cells. J Vet Sci, 5, pp. 11-8, 2004.

[32] Penttinen P, Vallius M, Tiittanen P, Ruuskanen J, Pekkanen J. Sourcespecific fine particles in urban air and respiratory function among adult asthmatics. Inhal Toxicol, 18, pp. 191-8, 2006.

[33] Anderson HR, Favarato G, Atkinson RW. Long-term exposure to air pollution and the incidence of asthma: meta-analysis of cohort studies. Air Qual Atmos Heal, 6, pp. 47-56, 2013.

[34] Fann N, Lamson AD, Anenberg SC, Wesson K, Risley D, Hubbell BJ. Estimating the national public health burden associated with exposure to ambient $\mathrm{PM}_{2.5}$ and ozone. Risk Anal, 32, pp. 81-95, 2012. 